DOI:

\title{
Análisis de factores de riesgo laboral en odontología
}

\author{
Analysis of occupational risk factors in dentistry \\ Juan José Hermoza Gutierrez ${ }^{\text {1a }}$, Adrián Calle Gutierrez ${ }^{\text {1a }}$, Anyelo Ururi Maye ${ }^{\text {1a }}$ \\ ${ }^{1}$ Escuela Profesional de Odontología, Universidad Nacional Jorge Basadre Grohmann. Tacna, Perú \\ ${ }^{a}$ Estudiante
}

\section{Resumen}

Se realizó una revisión bibliográfica con el objetivo de conocer los factores de riesgo más importantes que afectan la salud del profesional durante la práctica odontológica, los cuales son causados por no emplear la correcta ergonomía y bioseguridad en el consultorio dental. En este trabajo, se describen los riesgos químicos, físicos, psicológicos y biológicos, ya que estos conocimientos son importantes para que los estudiantes y profesionales en odontología tomen conciencia de los peligros en salud a los que están expuestos. Asimismo, este trabajo informa sobre medidas preventivas con el fin de disminuir las enfermedades de salud ocupacional. Finalmente, se resalta la necesidad de incentivar una cultura preventiva en bioseguridad y ergonomía enfática desde los primeros hasta los últimos años de la carrera odontológica, llevando un control continuo de tales contenidos. Es de suma importancia mencionar que las instituciones de salud y de formación profesional en salud requieren de un programa de bioseguridad con normas definidas y, también, de un ambiente laboral ordenado, seguro y de calidad.

Palabras claves: Bioseguridad, ergonomía, prevención, riesgos laborales

\begin{abstract}
This literature review aims to know the most important risk factors that affect the health of dental practitioners caused by not using the correct ergonomics and biosecurity in the dental office. Chemical, physical, psychological and biological risks are described in this work, being of importance the knowledge of these in order to become aware of the health hazards to which dentists and dental students are exposed. In addition, this investigation reports on preventive measures in order to reduce occupational health diseases. Finally, it is highlighted the need to encourage a preventive culture in biosafety and emphatic ergonomics from the first to the last year of the dental career, as well as keeping a continuous control of such contents. It is very important to mention that health care institutions and health professional training institutions should implement a biosafety program with well stablished standards along with an orderly, safe and quality work environment.
\end{abstract}

Keywords: Biosecurity, ergonomics, prevention, occupational hazards.

\section{Introducción}

Las enfermedades laborales son aquellas lesiones que se originan cuando el trabajador realiza un sobre esfuerzo físico o mental expuesto a ciertos factores de riesgo, perjudicando su salud y bienestar general.

La profesión odontológica es una disciplina biomédica con mayores riesgos a enfermedades. Las lesiones laborales más comunes que afectan a los odontólogos son los trastornos de músculos esqueléticos (TME), el síndrome del túnel carpiano (STC) y las lesiones ópticas. Los primeros, los TME, son daños que se generan en los tejidos musculares y cartílagos como producto de una mala postura al momento de realizar la atención al paciente. Esto, probablemente, debido al desconocimiento de las medidas ergonómicas adecuadas. Ya el segundo, el 
STC, se origina debido a la presión del nervio mediano a nivel de la muñeca; este se presenta, generalmente, por el uso de diversas herramientas usadas en el consultorio (1). En tercer lugar, se presenta las lesiones auditivas, las mismas que son generadas por la manipulación de piezas de mano, micromotores, recortadores de modelos, entre otros artefactos que emiten un ruido fuera del límite permisible generando la pérdida de la audición en el profesional odontólogo. Finalmente, las lesiones ópticas. La causa principal de estas afecciones es la exposición a la luz halógena sin protección. La ausencia de luz natural en los consultorios hace que se recurra a luces artificiales, las cuales con el paso del tiempo generan una disminución de la visión; asimismo, se puede generar refracciones ópticas (miopía, astigmatismo).

Todas estas afecciones laborales se inician como molestias leves, las cuales en la mayoría de casos, se deja pasar, pero con el transcurso del tiempo, estas se pueden intensificar y perjudicar el desempeño laboral del profesional.

El objetivo de la presente revisión es ofrecer la información actual sobre los riesgos laborales a los que están expuestos estudiantes de odontología y/o odontólogos, como también abordar la prevención de estas enfermedades con el fin de garantizar una mejor calidad de vida.

\section{Desarrollo}

Las lesiones ocupacionales de la carrera odontológica las podemos clasificar en 4 grandes grupos (2):

- Riesgos por agentes biológicos

- Riesgos por agentes físicos

- Riesgos psicológicos

- Riesgos por agentes químicos

A continuación, enumeraremos las afecciones en cada grupo y, seguidamente, desarrollaremos algunas de estas.

\section{Riesgos por agentes biológicos}

Por inoculación directa o contacto:

- Hepatitis B

- Síndrome de inmunodeficiencia adquirida

- Tétanos

- Herpes simple

- Panadizo

Por vía inhalatoria o saliva:

- IVTRS (Infecciones víricas del tracto respiratorio superior)

- Mononucleosis infecciosa

- Infección por citomegalovirus

- Infección por Helicobacter pylori
- Conjuntivitis infecciosa: bacteriana y víricas

\section{$1.1 \quad$ Hepatitis B}

Según la Organización Mundial de Salud y la FDI (Federación Dental Internacional), los odontólogos tenemos tres veces más riesgo de adquirir el virus de la hepatitis B debido a la elevada exposición a los fluidos corporales, sangre y saliva $(3,4)$. En un estudio realizado en 2009 , se halló que más de un tercio de la población mundial es perjudicada por el virus de la hepatitis B. Solo en España, casi del $1 \%$ de la población es portadora crónica y un $30 \%$ son infecciones activas con riego de evolucionar $(5,6)$.

La hepatitis B es una enfermedad que puede o no manifestar síntomas, por lo que el odontólogo puede encontrarse con portadores silenciosos; de esta forma, cualquier procedimiento oral se convierte en fuente de contagio.

En los últimos años, la prevalencia del VHB (Virus de la Hepatitis B) ha disminuido por diversos factores; por ejemplo, el personal de salud opta por medidas preventivas, tales como vacunas y barreras de protección, asimismo, el antígeno core ayuda en la detección de la infección de hepatitis B, además, este antígeno perdura indefinidamente (7).

Es importante tener en cuenta medidas de seguridad básica como el gorro, barbijo, mandilón y lentes de protección frente a estos agentes biológicos (8), así también, todo el personal de la clínica odontológica debe estar correctamente vacunado contra la hepatitis B $(9,10)$.

\section{Riesgos por agentes físicos}

- Radiaciones ionizantes

- Síndrome del túnel carpiano (STC)

- Patologías a nivel de columna: lumbalgias

- Pérdida de la audición

- Radiaciones por luz visible( luz halógena)

- Láser

- Campos electromagnéticos

- Heridas y cuerpo extraño ocular

- Patología producida por inhalación de polvo

\subsection{Patologías a nivel de columna: lumbalgia}

La lumbalgia es una de las enfermedades más comunes sobre las lesiones músculo - esqueléticas en profesionales de odontología; esto debido a la presencia de posturas erróneas en el consultorio. Los factores influyentes en la lumbalgia son la edad del odontólogo y la experiencia laboral del odontólogo (11).

En un estudio realizado en la Universidad privada de Tacna se determinó La alta prevalencia de lesiones asociados a futuros problemas músculo esqueléticos encontrado en los estudiantes de odontología donde de 206 estudiantes el 83 \% 
mencionó que estaba padeciendo problemas músculo esqueléticos (11). Estos resultados van de la mano con el trabajo clínico y los años académicos que el alumno lleva; en consecuencia, las escuelas odontológicas deben adoptar métodos de prevención que contribuyan a disminuir estos trastornos y aumentar en la calidad de vida de los estudiantes de la carrera de odontología.

Las posturas ergonómicas en la odontología son imprescindibles para el desempeño adecuado del profesional y brindar una correcta atención al paciente.

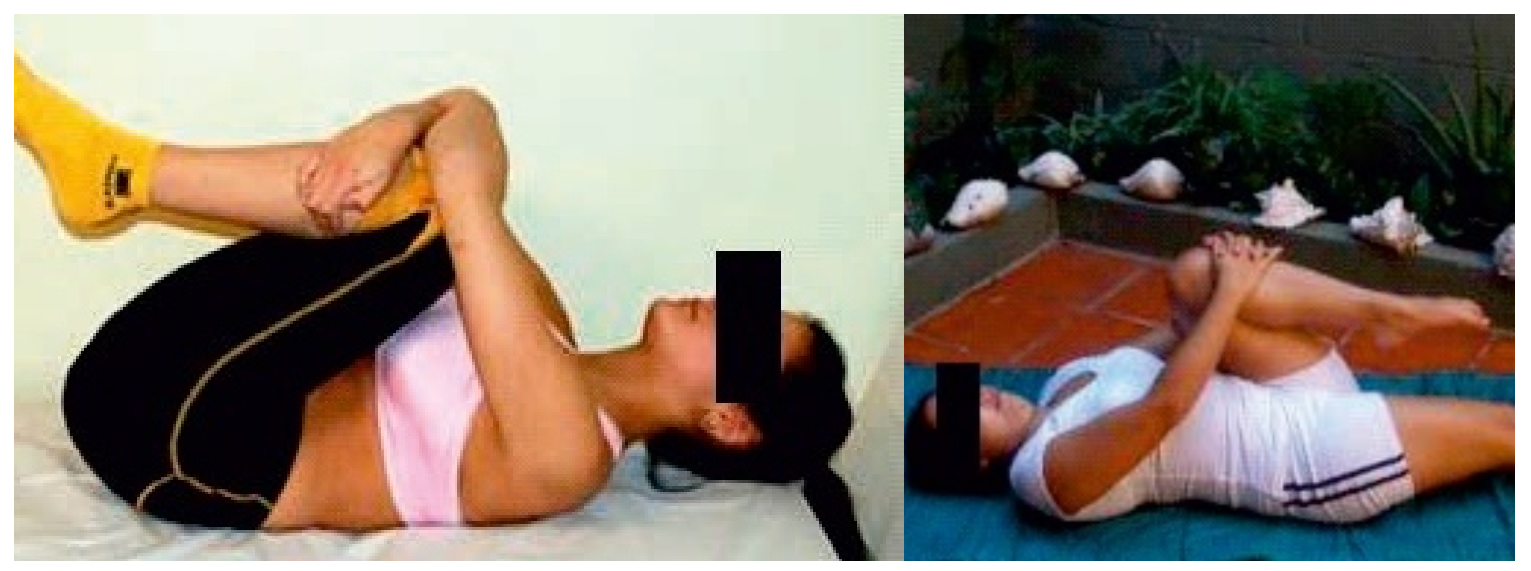

Figura 1. Pausas activas para disminuir dolor en la zona lumbar (11).

\subsection{Síndrome del túnel carpiano}

El síndrome de túnel carpiano es una enfermedad causada por la presión ejercida sobre el nervio mediano a nivel de la muñeca. Esa patología tiene una mayor ocurrencia en odontólogos profesionales por el constante uso de las herramientas usadas en el consultorio (1). En la actividad odontológica el síndrome del túnel carpiano es uno de los mayores problemas que implica no solo la salud del estomatólogo, si no también perturba sus diligencias profesionales (3).

En un estudio realizado en la ciudad de Sucre 2016 en el que participaron 64 odontólogos se reportó que el $62.5 \%$ de ellos no conoce el síndrome del túnel carpiano y eso actúa como un factor en la aparición de esta enfermedad; asimismo, el 78.1 \% tiene una jornada laboral de más de 6 horas; además, un $28.1 \%$ presentó falta de coordinación, un $23.4 \%$, pérdida de fuerza de oposición del pulgar y el $29.7 \%$ resultó positivo a la prueba de Tinel. Se afirmó una prevalencia del STC de $7.8 \%$ mediante los estudios de electromiografía y electro conducción (1).

Existen pautas que nos ayudan con un diagnóstico temprano, tales como la resonancia magnética, la electromiografía, el ultrasonido, estudios de conducción nerviosa y un buen historial clínico $(3,5)$. Se presentan dos alternativas referentes al tratamiento:

- No quirúrgica (conservador); la cual consiste en una introducción de férula, yoga, ultrasonido terapéutico, modificación terapéuticas y medicaciones.

- Quirúrgica (invasiva); esta se da cuando el dolor no puede ser detenido por la alternativa no quirúrgica y también cuando los síntomas son severos $(3,5,12)$.

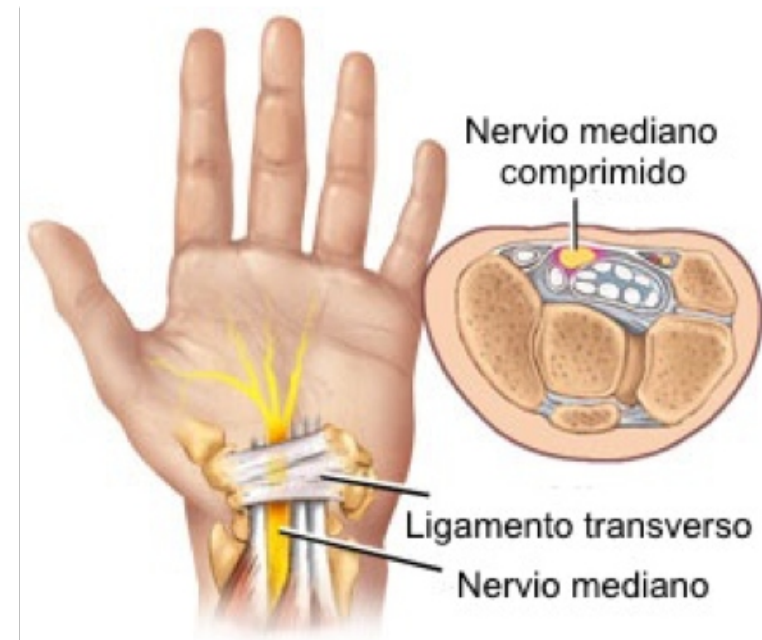

Figura 2. Síndrome del túnel carpiano (13).

\subsection{Pérdida de la audición}

Los estudiantes de odontología están expuestos a constante ruido desde el inicio de su formación profesional, lo que se considera dañino para su calidad de vida, el medio ambiente acústico se caracteriza por altos niveles de ruido en comparación con otras áreas de enseñanza. Esto se debe al ruido que producen algunos instrumentos dentales y además, al 
uso de los equipos por muchos usuarios a la vez. Esa situación se agrava cuando las salas de clases tienen superficies duras que actúan como reflectores de ruido (14), lo cual provoca una pérdida de audición irreversible (15).

Un estudio realizado en Tacna, de la UNJBG 2016 en estudiantes de la Escuela de Odontología, concluyó que un $62 \%$ presentaba audiometría normal; es decir, dentro del límite permisible (DLP) y un $43.2 \%$ presentaba hipoacusia ligera, fuera del límite permisible (FLP). Además, se observó que los niveles de ruido ocupacional era de mayor porcentaje en DLP en el primer año; mientras que en el IV y V año, el mayor porcentaje estaba en FLP. También, se encontró que los estudiantes con más años de exposición a ruido odontológico presentaron peor desempeño en las pruebas audiométricas (16).

Como medidas preventivas, se recomienda el mantenimiento regular de las unidades dentales, el empleo de equipos dentales modernos menos ruidosos, el acondicionamiento acústico de las áreas clínicas y preclínicas en escuelas de odontología, y el uso de tapones auditivos obligatorios.

\subsection{Lesiones oftálmicas}

La odontología es una ciencia muy diversa, puesto que abarca múltiples aspectos asociados a la cavidad oral. Uno de estos aspectos es la rehabilitación oral, la cual tiene como aspecto primordial la estética. Para ello, se hace uso de materiales de restauración, los cuales están en constante evolución (17); asimismo, se hace uso de diversos instrumentales para llevar a cabo esta labor; uno de los instrumentales más usados en esta rama odontológica es la lámpara de luz halógena, cuya intensidad debe medirse con cuidado puesto que, según algunos estudios, pueden generar daños en la retina (18).

Según un estudio realizado a 28 estudiantes de odontología de la Universidad del Valle en 2007, respecto a los las condiciones oftalmológicas, se obtuvo como resultados que el $64.29 \%$ de estudiantes que utilizaron la lámpara de fotocurado presentaron lesiones oculares, mientras que el $42.86 \%$ de estudiantes que no usaron la lámpara ya presentaban un daño ocular. También, se descubrió que el $58.30 \%$ de estudiantes presentaban miopía, el $33.30 \%$ presentaba astigmatismo y el $8.30 \%$ presentaba hipermetropía (19).

Se recomienda el uso de gafas de protección para evitar lesiones oculares, asimismo, guardar distancia mayor a $25 \mathrm{~cm}$ respecto a la zona de exposición a esta luz(19).

\section{Riesgos por sobrecarga de trabajo}

Por sobrecarga psicológica

- Estrés laboral

- Síndrome de desgaste profesional (Burnout)

\subsection{Síndrome de desgaste profesional (Burnout)}

El síndrome de Burnout se ha descrito en tres fases: agotamiento emocional, despersonalización y falta de realización personal.

Existen variables que tiene relación con este síndrome como el género del odontólogo y sus años de formación en la carrera; siendo el agotamiento emocional, el más común entre los estudiantes. El agotamiento emocional se entiende como la escasez de los pensamientos emocionales a tal punto que el que lo padece de esto piensa que no podrá dar más de sí en las actividades que realiza $(20,21)$.

Este síndrome afecta al personal de salud principalmente. Muchas publicaciones demuestran una prevalencia global a nivel de Latinoamérica exceptuando Paraguay- de 11.14 \% (22). Algunos autores afirman que los síntomas de este síndrome afligen a todo el personal de salud en algún momento de su carrera (23). En una encuesta realizada en el año 2016 sobre la prevalencia del síndrome de burnout, se halló que el $6 \%$ de todos los encuestados se encontraba en un nivel muy alto de este síndrome, y un $29 \%$ en un nivel alto (24).

La forma idónea de prevenir este síndrome es un término llamado "resiliencia" que consiste en afrontar y sobreponerse a este síndrome tan problemático (22).

\section{Riesgos por agentes químicos}

Eczema alérgico de contacto o dermatitis por

- Látex

- Resinas acrílicas

- Metales: cromo, níquel, cobalto

- Yodo y desinfectantes

- Irritantes y sensibilizantes respiratorios

- Gramíneas (de guantes)

- Hipoclorito sódico, glutaraldehído

- Intoxicación crónica por mercurio

\subsection{Alergia al látex}

El látex es uno de los principales causantes de reacciones alérgicas, especialmente en el campo odontológico, ya que al estar expuesto a este material a través de la vía cutánea, se genera urticaria de contacto y en casos extremos la anafilaxia. Es importante destacar que la urticaria es una de las reacciones alérgicas que más padecen los odontólogos en el campo laboral(26).

Según un estudio realizado en el año 2015 en la Universidad Central de Venezuela a 124 personas entre estudiantes y docentes de la clínica odontológica de la Corporación Universitaria Rafael Núñez, se obtuvo como resultado que el $12 \%$ presentaba una 
reacción alérgica por contacto al látex. El tipo de reacción que los participantes manifestaban presentar al estar en contacto con el látex fue prurito en $6.45 \%$ y dermatitis en $3.23 \%$. En cuanto al tiempo trascurrido entre el contacto con el látex y la reacción, el $4.07 \%$ respondió que la reacción fue inmediata y el otro $4.07 \%$ que fue 1 hora después. La prevalencia de reacciones alérgicas por contacto con guantes de látex reportada en la presente investigación fue de $9.68 \%$, para una muestra de 124 individuos encuestados (27).

El método de prevención para las personas que padecen este tipo de alergias es el tratamiento farmacológico (26).

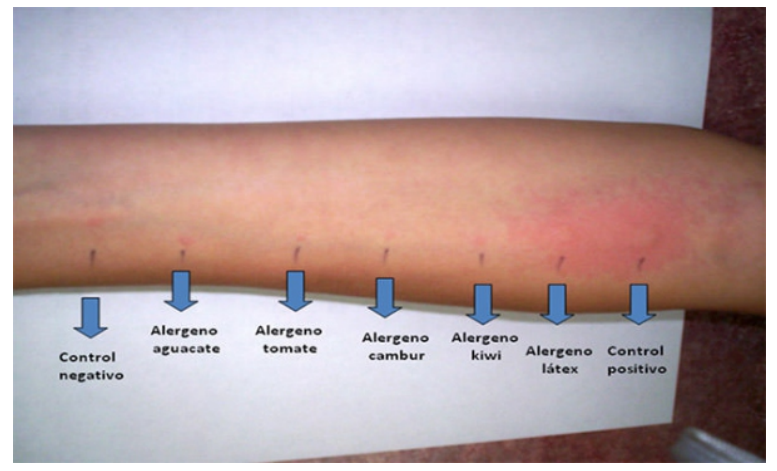

Figura 3. Resultado de las lesiones cutáneas frente al látex (26).

\section{Conclusiones}

Se concluye que los factores de riesgo laboral son un gran problema que comprometen el bienestar físico, psicológico y por ende afectan directamente su desempeño laboral.

Se observó que las lesiones ocupacionales más comunes desde la formación del profesional odontólogo fueron: la lumbalgia, síndrome del túnel carpiano y el síndrome de burnout.

\section{Recomendaciones}

Es de importancia determinar las consecuencias de los peligros y la probabilidad de riesgo durante los procedimientos odontológicos, lo que nos lleva a crear estrategias de control y métodos para minimizar estos riesgos laborales.

Se debe tener en cuenta una cultura preventiva en bioseguridad y ergonomía enfática desde los primeros años de la carrera odontológica, hacer el control continuo, permanente, y afianzarla en los últimos años de estudios odontológicos.

Las instituciones de formación profesional en salud y propiamente de salud, requieren de un programa de bioseguridad y ergonomía con normas definidas que consigan un ambiente laboral ordenado, seguro y de calidad para el estudiante de odontología, el profesional odontólogo y el paciente.

\section{Referencias bibliográficas}

1. Escudero E, Aprili L, Muñoz V, de la Cruz M, Moscoso M. "Prevalencia del síndrome del túnel carpiano de origen laboral en odontólogos de la Ciudad de Sucre". Revista Ciencia, Tecnología e Innovación, 2016; 13 (14): 805-814.

2. Dr. J. Carrión, Riesgos para la salud en profesionales de la Odontología, Gaceta dental, [Publicación periódica en línea] 19 de enero de 2012. [citado 2019, 7 de noviembre ] Disponible en: shorturl.at/chiU5

3. De Juanes, JR, Arrazola MP, Domínguez V y cols. Problemática de los agentes biológicos en la práctica odontológica. Normas en la clínica diaria. Avances en Odontología, 1996; 12 (4):277-92.

4. Reichart PA. AIDS and hepatitis: a problem for the team. Int Dent J., 1994; 44: 49-54

5. Alter MJ, Hadler SC, Margolis HS y cols. The chan Ging epidemiology of hepatitis B in the United States. JAMA, 1990; 263: 1218-22.
6. Aguilera Guirao A, Romero Yuste S y Regueiro BJ. Epidemiología y manifestaciones clínicas de las hepatitis virales. Enferm Infecc Microbiol Clin 2006; 24(4): 264-76.

7. Hoofnagle JH. Chronic hepatitis B. N Engl J Med 1990; 323: 337-9.

8. Pareja-Pané, Germán, Riesgo de transmisión de enfermedades infecciosas en la clínica dental, 2004.

9. Juanes JR, Arrazola MP de Juanes A, Lago E, Rocha M, Gil P.Bascones A. Riesgos virales en odontoestomatología. Campaña de vacunación frente a hepatitis. Au. Odontoestomatologica, 2003: 19-1:21-28.

10. Vignarajah S, Eastmond VH, Ashraph A y cols. An Assesment of cross-infection control procedures Among English-speaking Caribbean general dental Practitioners. A regional preliminary study. Int Dent J., 1998; 48: 67-76

11. Cleveland JL, Siew C, Lockwood SA y cols. Hepatitis B vaccination and infection among U.S.dentists, 1983/1992 J Am Dent Assoc., 1996; 
127:1385-90.

12. Rojo Marcos G, Cuadros González J, Arranz Caso A. Enfermedades infecciosas importadas en España. Med Clin 2008; 131: 540-50.

13. M. Cámara. Síndrome del túnel carpiano. Ciudad Real, España. Enfermería Ciudad Real; s [Publicación periódica en línea] 13 de abril 2018. [citado 2019, 7 de noviembre ]. Disponible en: https://www.enfermeriadeciudadreal.com/sindrom e-del-tunel-carpiano-707.htm

14. Montesinos V. Factores de riesgo físico y dolor lumbar en un grupo de odontólogos en la ciudad de Tacna-2017. Revista Médica Hospital Hipólito Unánue, 2018; 11(1).

15. Sampaio, J et al. Noise levels in dental schools. European journal of Dental Education, 2006; 10: 32-37.

16. Goelzer, B. Hansen, C. \& Sehrndt, G. Occupational exposure to noise: evaluation, prevention and control. World Health Organization by the Federal Institute for Occupational Safety and Health, Dortmund, Germany; 2001.

17. Martínez N. Niveles de audiometría y su relación con el ruido ocupacional en estudiantes de la escuela profesional de odontología de la UNJBG de Tacna 2016. Revista Médica Basadrina.12 (2).2127.

18. Visible light-cured composites and activating units. Council on Dental Materials, Instruments, and Equipment. J Am Dent Assoc.,1985; 110(1):100102.

19. Arias Montoya LA. Efectos lesivos potenciales de la luz de polimerización sobre el órgano de la visión. Rev Fac Odontol Univ Antioq., 1993; $4(2): 31-37$.

20. Giraldo A, Hernández AM, Jaramillo I., Lerma M., Zamora I. Examen oftalmológico en estudiantes de odontología y su relación con el uso de la lámpara de fotocurado, Revista estomatológica, 2010. 18(2): 7-10
21. Maslach C. Jackson S. The measurement of experienced burnout, Journal of Organ Behavior; 1981,2(2), 99-113

22. Perez C, Parra P, Fasce E, Ortiz L, Bastias N, Bustamente $\mathrm{C}$, et al. Estructura factorial y confiabilidad del Inventario de burnout de Maslach en universitarios chileno. Revista argentina de Clínica Psicológica, 2012; 21(3) 255-63

23. Grau A, Flichtentrei D, Suñer R, Font-Mayolas S, Prats M, Braga F. El Burnout percibido o sensación de estar quemado en profesionales sanitarios: prevalencia y factores asociados. Inf Psicol, 2007; 91:64-79.

24. Díaz Romero RM, Lartigue Becerra T, Acosta Velasco ME. Síndrome de Burnout. Desgaste emocional en cirujanos dentistas. Rev Asoc Den Mex., 2001;58 (2):63-7.

25. C. Anaya. El síndrome de burnout en los dentistas en España. [Tesis para optar de grado de doctor en cirugía y odontoestomatologia]. Salamanca: Universidad de Salamanca, 2016

26. Pimentel H., Alergia al látex en una profesional de la odontología[Publicación periódica en línea]2015.Marzo [Citada 20194 de noviembre] 53, (1): [aproximadamente $10 \mathrm{pp}$ ] Disponible en: shorturl.at/oxyDK

27. López S, Jessica1, Fortich M, Natalia , Arias N, Freddy , Gordon L, Luis, Primera C, Dayana, Prevalencia de reacciones alérgicas por contacto con guantes de látex en los estudiantes y docentes de la clínica odontológica de la corporación universitaria Rafael Núñez. Ciencia y salud, 2010; 2:
Correspondencia:
juanhermoza2019@gmail.com
Fecha de recepción : 05 de julio de 2019

Fecha de aceptación : 01 de noviembre de 2019 